\title{
Nephroendocrinology: When endocrinology meets nephrology
}

\author{
Edgar V. Lerma ${ }^{1}$ - Christian A. Koch ${ }^{2,3,4}$
}

Published online: 23 March 2017

(C) Springer Science+Business Media New York 2017

During residency in internal medicine at the Ohio State University in Columbus, OH, USA, CAK was fortunate to train with top-notch nephrology faculty members including N. Stanley Nahman, Michael Falkenhain, Brad Rovin, Lee Hebert, and Anil Agarwal and was encouraged to pursue a career in nephrology, which to him always has been a fascinating field. It is intertwined with many other specialties of medicine including endocrinology, and some of our colleagues including Professor Hartmut Neumann are board certified in both endocrinology and nephrology [1]. Systemic disorders such as diabetes mellitus and autoimmune disease can affect the kidneys, and vice versa, disorders (such as renal osteodystrophy) can ensue on the basis of acute or chronic kidney disease. Chronic kidney disease worldwide has been reported to be prevalent in $10 \%$ to $15 \%$ of the general population, and the treatment of patients with kidney disease represents a complex challenge [2,3]. Endocrine disrupting chemicals including heavy metals may contribute to the development and progression of chronic kidney disease [4-6]. There is known considerable overlap between nephrology and endocrinology, borne by common pathophysiologic inter-relationships. Although the kidney plays a central role in body

Edgar V. Lerma

nephron0@gmail.com

1 Section of Nephrology, University of Illinois at Chicago College of Medicine/Advocate Christ Medical Center, Oak Lawn, IL, USA

2 Division of Endocrinology, Diabetes, Metabolism, University of Mississippi Medical Center, Jackson, MS, USA

3 G.V. (Sonny) Montgomery VA Medical Center, Jackson, MS, USA

4 Cancer Institute, University of Mississippi Medical Center, Jackson, MS, USA homeostasis, i.e., fluid and electrolyte balance, as well as regulatory control of blood pressure, one has to realize that it is not simply an excretory organ, as it exerts multiple endocrine functions, in fact, playing a significant role involving hormones involved in the renin-angiotensin-aldosterone system, erythropoietin, as well as 1,25 dihydroxy vitamin D3. Aside from producing enzymes, i.e., kallikreins, it also produces socalled local hormones, i.e., prostaglandins, endothelins, and adrenomedullin. Similarly, it is the primary target of other hormones, i.e., aldosterone, cortisol, angiotensin, and the natriuretic peptides $[7,8]$.

With kidney disease being the 9th leading cause of death in the United States, it is important for clinicians to understand various endocrinological aspects that may affect such patients as it has crucial implications in management and prognosis.

I (CAK) am very delighted to introduce nephrology expert Dr. Edgar Lerma as the Guest Editor for this special issue of Reviews in Endocrine \& Metabolic Disorders. Dr. Lerma has recently participated in a global expert conference on managing patients with diabetes and chronic kidney disease and has edited the book "Chronic Kidney Disease and Hypertension" [9, 10]. For this journal issue, Dr. Lerma assembled a panel of expert contributors from around the globe to discuss aspects of various endocrine disorders in patients with chronic kidney disease.

With the prevalence of diabetes around the world reaching epidemic proportions, the first set of articles in this issue is dedicated to this topic. Garla and colleagues [11] illustrate the challenges of glycemic management in patients with diabetes mellitus and chronic kidney disease. Hypoglycemia and glucose variability, especially in elderly, should be minimized [12]. Novel biomarkers for diabetic nephropathy and new insights into its pathophysiology are discussed by Ilyas and colleagues [13]. Besides 
diabetes mellitus, patients with chronic kidney disease have other factors, including hyperlipidemia, putting them at high risk for cardiovascular disease. Hager and colleagues [14] provide a nice overview on mechanisms underlying dyslipidemia in such patients and clinical trial evidence for lipid lowering therapy, discussing recently published guidelines pertaining to dyslipidemias as developed by various organizations, and how to apply them to everyday clinical practice.

The next series of articles is dedicated to electrolyte and water homeostasis, starting with an update on hyperkalemia including new therapeutic agents [15]. Disturbances in sodium and water balance including hyponatremia, hypernatremia, dehydration, and age-related kidney changes are then reviewed by Koch and Fulop [16], followed by an excellent review on hyponatremia and bone disease by Negri and Ayus [17], pointing out the importance to consider a bone density scan in patients with hyponatremia and to check a serum sodium concentration in (elderly) patients presenting with an orthopedic injury/fracture.

The third set of articles is related to bone in patients with chronic kidney disease, starting out with an overview of secondary hyperparathyroidism, including tools for its possible prevention [18]. With the increasing number of kidney transplantations in diabetic and other patients, it becomes important to understand pathophysiological processes posttransplantation such as osteoporosis which is reviewed by the nephroendocrinology team Gosmanova and Gosmanov [19]. Secondary causes of osteoporosis include hyperthyroidism, glucocorticoid excess, sex hormone deficiency, and others. Short stature not only can result from growth hormone deficiency, thyroid hormone deficiency, or glucocorticoid excess in childhood, but also from abnormalities in calciumphosphate homeostasis. Although he is an adult endocrinologist, CAK has received several consults for short stature, sometimes from grown men with "Short Man syndrome" which in Wikipedia is reported as "Napoleon complex" and "characterized by overly aggressive or domineering social behavior, driven by a perceived handicap to overcompensate in other aspects of their lives" (https://en.wikipedia.org/wiki/ Napoleon_complex). For individuals with short stature from $\mathrm{X}$-linked hypophosphatemia, the most common form of hereditary rickets, there is potentially good news: treatment with growth hormone can accelerate longitudinal growth rate according to studies conducted by senior author Professor Santos. He and his colleagues provide an overview of this condition, summarizing current knowledge of phosphorus metabolism in individuals with X-linked hypophosphatemia and effects of fibroblast growth factor 23 on the epiphyseal growth plate of a mouse animal model [20]. The last two articles in this issue are dealing with abnormalities in the hypothalamo-pituitary-gonadal and the hypothalamopituitary-thyroid axis. Palmer and Clegg review sexual dysfunction in men and women with chronic kidney disease pointing out that successful kidney transplantation is the most effective way to restore normal sexual function in such patients [21]. Testosterone deficiency is regarded a risk factor for cardiovascular disease and testosterone therapy in selected patients can improve overall health with more data on this topic still evolving [22-25].

Iglesias and colleagues [26] conclude this guest issue and illustrate how challenging it can be to manage patients with chronic kidney disease and (abnormal) thyroid function tests.

\section{Compliance with ethical standards}

Conflict of interest statement The authors declare that they have no conflict of interest.

\section{References}

1. Glasker S, Neumann HPH, Koch CA, Vortmeyer AO. Von Hippel Lindau syndrome (chapter 35, Section: GP Chrousos). In: Leslie DeGroot (ed.). www.endotext.com; June 2015, in PUBMED: http://www.ncbi.nlm.nih.gov/books/NBK279124/.

2. Eckardt KU, Coresh J, Devuyst O, Johnson RJ, Köttgen A, Levey AS, et al. Evolving importance of kidney disease: from subspecialty to global health burden. Lancet. 2013;382(9887):158-69.

3. GBD 2015 Mortality and Causes of Death Collaborators. Global, regional, and national life expectancy, all-cause mortality, and cause-specific mortality for 249 causes of death, 1980-2015: a systematic analysis for the Global Burden of Disease Study 2015. Lancet. 2016;388(10053):1459-544.

4. Fowler BA. Mechanisms of kidney cell injury from metals. Environ Health Perspect. 1993;100:57-63.

5. Wasana HM, Perera GD, Gunawardena PS, Fernando PS, Bandara J. WHO water quality standards Vs Synergic effect(s) of fluoride, heavy metals and hardness in drinking water on kidney tissues. Sci Rep. 2017;7:42516. doi:10.1038/srep42516.

6. Koch CA, Diamanti-Kandarakis E. Introduction to endocrine disrupting chemicals-is it time to act? Rev Endocr Metab Disord. 2015;16(4):269-70.

7. Singh AK, Williams GH (eds), Textbook of nephro-endocrinology, Academic Press; 1st edition (December 19, 2008), ISBN-13: 978 0123738707 ISBN-10: 0123738709.

8. Kochanek M, Said A, Lerma EV. Mineral metabolism in chronic kidney disease. Dis Mon. 2015;61(10):425-33.

9. Perkovic V, Agarwal R, Fioretto P, Hemmelgarn BR, Levin A, Thomas MC, et al. Conference participants. Management of patients with diabetes and CKD: conclusions from a "Kidney Disease: Improving Global Outcomes" (KDIGO) controversies conference. Kidney Int. 2016;90(6):1175-83.

10. Koch CA, Pamporaki C, Kantorovich V. Endocrine hypertension and chronic kidney disease (chap.16). In: Weir MR, Lerma EV, editors. Chronic kidney disease and hypertension. New York: Springer; 2015.

11. Garla V, Yanes-Cardozo L, Lien LF. Current therapeutic approaches in the management of hyperglycemia in chronic renal disease. Rev Endocr Metab Disord. 2017. doi:10.1007/s11154-017-9416-1.

12. Hodge M, McArthur E, Garg AX, Tangri N, Clemens KK. Hypoglycemia incidence in older adults by estimated GFR. Am J Kidney Dis. 2017 Jan 27. 
13. Ilyas Z, Chaiban JT, Krikorian A. Novel insights into the pathophysiology and clinical aspects of diabetic nephropathy. Rev Endocr Metab Disord. 2017. doi:10.1007/s11154-017-9422-3.

14. Hager MR, Narla AD, Tannock LR. Dyslipidemia in patients with chronic kidney disease. Rev Endocr Metab Disord. 2016. doi:10. 1007/s11154-016-9402-z.

15. Kovesdy CP. Updates in hyperkalemia: outcomes and therapeutic strategies. Rev Endocr Metab Disord. 2016 Sep 6. doi:10.1007/ s11154-016-9384-x.

16. Koch CA, Fulop T. Clinical aspects of changes in water and sodium homeostasis in the elderly. Rev Endocr Metab Disord. 2017. doi:10. 1007/s11154-017-9420-5

17. Negri AL, Ayus JC. Hyponatremia and bone disease. Rev Endocr Metab Disord. 2016 Sep 24. doi:10.1007/s11154-016-9387-7.

18. Rodriguez M, Rodriguez-Ortiz ME. Secondary hyperparathyroidism: pathogenesis, diagnosis, preventive, and therapeutic strategies. Rev Endocr Metab Disord. 2017. doi:10.1007/ s11154-017-9421-4.

19. Gosmanova EO, Gosmanov AR. Osteoporosis in patients with diabetes after kidney transplantation. Rev Endocr Metab Disord. 2016 Nov 19. doi:10.1007/s11154-016-9397-5.

20. Fuente R, Gil-Peña H, Claramunt-Taberner D, Hernández O, Fernández-Iglesias A, Alonso-Durán L, et al. X-linked hypophosphatemia and growth. Rev Endocr Metab Disord. 2017. doi:10.1007/s11154-017-9408-1.

21. Palmer BF, Clegg DJ. Gonadal dysfunction in chronic kidney disease. Rev Endocr Metab Disord. 2016 Sep 1. doi:10.1007/s11154016-9385-9.

22. Ullah MI, Washington T, Kazi M, Tamanna S, Koch CA. Testosterone deficiency as a risk factor for cardiovascular disease. Horm Metab Res. 2011;43(3):153-64.

23. Ruige JB, Ouwens DM, Kaufman JM. Beneficial and adverse effects of testosterone on the cardiovascular system in men. J Clin Endocrinol Metab. 2013;98(11):4300-10. doi:10.1210/jc.2013-1970.

24. Morgentaler A, Zitzmann M, Traish AM, Fox AW, Jones TH, Maggi $\mathrm{M}$, et al. Fundamental concepts regarding testosterone deficiency and treatment: international expert consensus resolutions. Mayo Clin Proc. 2016;91(7):881-96. doi:10.1016/j.mayocp.2016.04.00.

25. Traish AM. Testosterone therapy in men with testosterone deficiency: are the benefits and cardiovascular risks real or imagined? Am J Physiol Regul Integr Comp Physiol. 2016;311(3):R566-73.

26. Iglesias P, Bajo MA, Selgas R, Díez JJ. Thyroid dysfunction and kidney disease: an update. Rev Endocr Metab Disord. 2016 Nov 18.

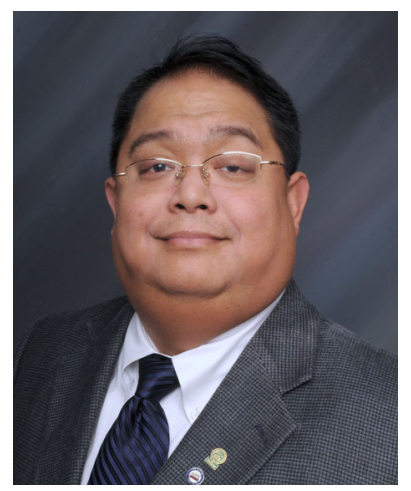

Edgar Lerma MD, earned his Doctor of Medicine from the University of Santo Tomas Faculty of Medicine and Surgery in Manila, Philippines. He completed his Residency Training in Internal Medicine at UIC/Mercy Hospital and Medical Center, where he also served as Chief Resident. He completed a fellowship in nephrology and hypertension at Northwestern Memorial Hospital, the Feinberg School of Medicine at Northwestern University, and the Veterans Administration Lakeside Medical Center in Chicago, Illinois.

Dr. Lerma is a diplomate in the subspecialty of nephrology with the American Board of Internal Medicine. He has authored more than 100 peer-reviewed publications and presentations; notable publications include Current Diagnosis \& Treatment: Nephrology \& Hypertension, Nephrology Secrets, and Henrich's Principles and Practice of Dialysis. He has peer-reviewed and served on editorial boards for numerous peer-reviewed journals, and currently serves as Associate Editor for Clinical Reviews in Bone and Mineral Metabolism, Reviews in Endocrine and Metabolic Disorders, and Journal of Clinical Lipidology; and Section Editor of Geriatric Nephrology for the International Urology and Nephrology.

At present, he holds the rank of Clinical Professor of Medicine with the Section of Nephrology at University of Illinois at Chicago. He serves as the Educational Coordinator for Nephrology with UIC/ Advocate Christ Medical Center.

In recognition of his clinical work and expertise, Dr. Lerma has been elected to Fellowship of the American College of Physicians, Fellowship of the American Society of Nephrology, Fellowship of the American Heart Association/Council on Kidney in Cardiovascular Disease, Fellowship of the American Society of Hypertension, Fellowship of the National Lipid Association, Fellowship of the National Kidney Foundation, and Fellowship of the American Society of Diagnostic and Interventional Nephrology. He has also been recognized for teaching and has been the recipient of "Subspecialty Teaching Attending Physician of the Year" in 2006 and "Physician Recognition Award for Excellence in Academics" in 2011 from UIC/Advocate Christ Medical Center Internal Medicine Residency Training Program.

Dr. Lerma's research interests include CKD, hypertension, bone and mineral disorders, and dyslipidemias in CKD.

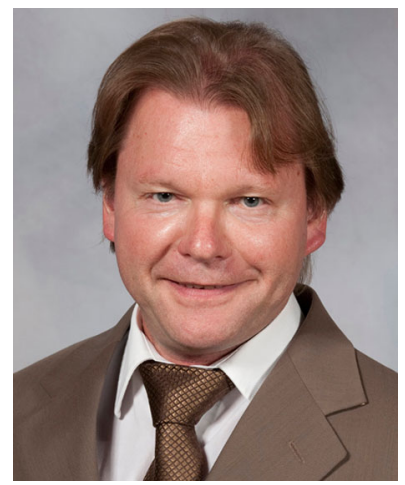

Prof. Christian Koch 